\title{
Drama and Theatre
}

Books and Journals from Cambridge University Press

We are the world's leading publisher in theatre and drama books and journals, with a wide-ranging coverage of the discipline.

Our publishing encompasses theatre history, performance theory and studies, Shakespeare, regional drama and popular theatre.

We publish the journals of the American Society for Theatre Research, the Congress on Research in Dance, and the International Federation for Theatre Research, and provide books for all areas of the market, including university libraries, scholars, students, and theatre enthusiasts.

For further details visit: cambridge.org/core-theatre

\section{Cambridge Core}




\section{CAMBRIDGE}

\section{EXCLUSIVE 10\% DISCOUNT USE DISCOUNT CODE: CUPjournals

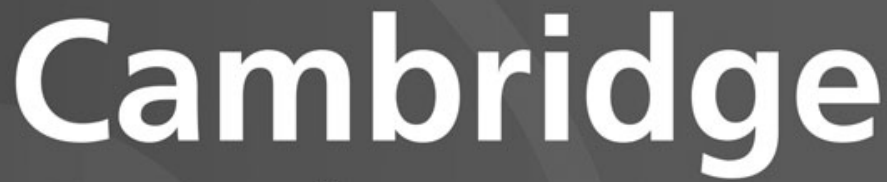 Author

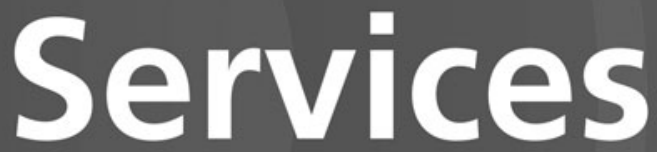 \\ Get your manuscript submission ready}

- Cambridge University Press and American Journal Experts are working together to help you prepare your manuscript for submission.

- We offer Premium Language Editing, Translation, Formatting, Poster and Figure Preparation for academic manuscripts by PhD level experts, covering over 420 areas of study.

- Get started today, visit cambridge.org/authorservices

AJE. AmErican JOURnal Experts
CAMBRIDGE UNIVERSITY PRESS 

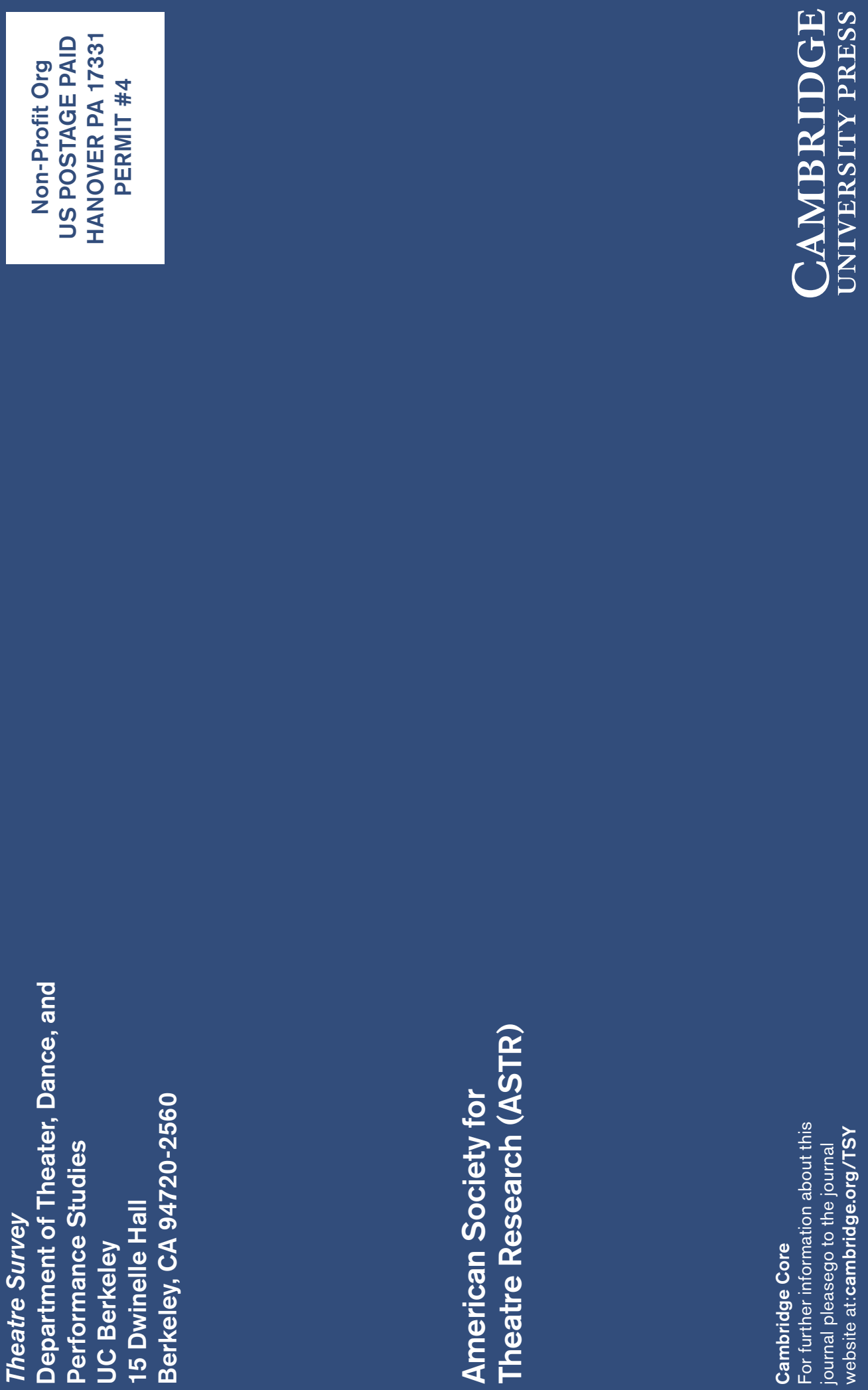